\title{
Study on Daily ET Based on SEBAL Model in a Typical Watershed of the Loess Plateau of China
}

\author{
Xuexia Zhang1*, Yu Fang1, Yuepeng Gao', Xinxiao Yu' ${ }^{1}$, Dianjun Zhang ${ }^{2}$ \\ ${ }^{1}$ College of Soil and Water Conservation, Beijing Forestry University, Beijing, China \\ ${ }^{2}$ School of Marine Science and Technology, Tianjin University, Tianjin, China \\ Email: *zhangxuexia@bjfu.edu.cn
}

How to cite this paper: Zhang, X.X., Fang, Y., Gao, Y.P., Yu, X.X. and Zhang, D.J. (2019) Study on Daily ET Based on SEBAL Model in a Typical Watershed of the Loess Plateau of China. Journal of Water Resource and Protection, 11, 181-199. https://doi.org/10.4236/jwarp.2019.112011

Received: December 21, 2018

Accepted: February 16, 2019

Published: February 19, 2019

Copyright $\odot 2019$ by author(s) and Scientific Research Publishing Inc. This work is licensed under the Creative Commons Attribution International License (CC BY 4.0).

http://creativecommons.org/licenses/by/4.0/

\begin{abstract}
Under the double impact of global climate change and human intervention, surface evapotranspiration (ET), as an important part of hydrological cycle, is affecting watershed land-use planning and economic development. The Loess Plateau is mostly arid and semi-arid areas and its ecological environment is fragile. Drought and soil erosion not only reflects the regional climate change, but also human social activities and ecosystems. In particular, these processes are directly related to the thermal and water gradients exchange in the soil-vegetation-atmosphere system. Luoyugou watershed, a typical Loess Plateau watershed, is selected for this study. Estimating ET through SEBAL (Surface Energy Balance Algorithm for Land) model demonstrates that the SEBAL model in the watershed is more applicable. At the same time, ET seasonal variation is got, combined with the corresponding periods of the land-use changes for analysis. The results show that ET in the Northwest of the basin is higher than the East on the spatial distribution, especially in the high vegetation coverage area. Land use changes significantly in the watershed over the past 20 years, mainly transferring from sloping terraces to the terraces and woodland. ET significantly increased area accounts for $47.6 \%$ of the total area in the valley, however, conspicuously reduced area accounts for $13.2 \%$. The daily ET of different land use types had significant differences with the ET of water land and wood land was the largest. It is important that this study on the ET distribution can aid policy and decision makers for land use planning and environmental construction in Luoyugou watershed.
\end{abstract}

\section{Keywords}

Daily ET, SEBAL Model, Climate Change, The Loess Plateau of China 


\section{Introduction}

ET is an important element in the process of terrestrial water and energy cycle, and the exchanges between the moisture and its carrying latent heat in the terrestrial hydrological processes among the oceans and land regulate the global distribution of water and energy. In a specific area, water and energy cycles can directly affect its temporal and spatial distribution of water resources, thereby affecting the regional economic and social development [1]. Since 1802, the formula for calculating evaporation proposed by Dalton, the estimation on ET has achieved important progress in both theory and practice, such as the Bowen Ratio-energy balance method, aerodynamic method, and eddy correlation method [2] [3]. Because of the land surface spatial heterogeneity, the traditional observation methods are difficult to expand from the point to surface. From 1970s, the appearance of remote sensing technology gave great impetus for the study on ET and accelerated the emergence and improvement of remote sensing retrieval models. There are many remote sensing retrieval models which can be divided into three categories, namely, the mechanism model, empirical model and semi-empirical model. Among of them, empirical model is based on relevant parameters to measure ET or fitting a regression analysis to get the relationships. Empirical model is simple and easy to operate, but it lacks the strict definition for physical meaning and a fitting return has certain randomness. It is prone to bring about large errors in the process. Generally, semi-empirical model can derive instantaneous or daily ET by the parameters obtained from remote sensing information easily which needs less input parameters to be well simulated a variety of different vegetation coverage of the underlying complex surface ET, but it requires more meteorological factors. Some of the elements can be obtained only by assuming to solve. Although the empirical and semi-empirical models in practical applications have played a large role, the most widely used is the mechanism model. There are many models based on energy balance principle, including the single-layer model, double-layer model and Penman model. One relatively mature application of the model is SEBAL model proposed by Bastiaanssen [4], whose basic principle is energy balance. It is a typical method through the inversion of ET by remote sensing technology that has been verified in a number of places at home and abroad. Compared with the traditional manual measurement method, the RS-based inversion method requires less data and is less affected by the underlying surface condition. It can dynamically observe the temporal and spatial changes of the target area, so it is the main method to study regional evapotranspiration at present because of economy and applicability.

There are various ET models for estimating different components of the energy balance, including the Two Source Model (TSM), Surface Energy Balance Index (SEBI), Surface Energy Balance Algorithm for Land (SEBAL), Surface Energy Balance System (SEBS) SEBI model was proposed by Menenti based on crop water stress index, the model utilizes a set of boundary layer characteristic 
parameters (potential temperature, wind speed, humidity, etc.) to calculate daily ET. SEBS model is proposed on the basis of SEBI model which use image data to inverse surface parameters. TSM is a two-layer energy balance model applicable to uniform underlying surface. Among these methods, SEBAL is well established and extensively used in different climate and land use conditions. With a solid physical mechanism, few parameters, higher reliability and can be used to calculate regional long-term and large-scale surface evapotranspiration. SEBAL has stood the test of time with over 20 years of successful application under various hydro-climatic and agronomic conditions. Due to these major advantages of this surface energy balance model, it was adopted for the spatial estimation of ET in the Loess Plateau of China.

Satellite-based studies of ET have the advantage that they provide observations which are spatially extensive and temporally frequent. Numerous satellite-based analyses of ET have been undertaken using Landsat sensors because of the length of the data archive available [5] [6]. Most commonly, these analyses combine satellite images with SEBAL model to get ET and have a very high precision. In Idaho State of the United States, the seasonal map drawn by SEBAL model had been used to predict the amount of groundwater and the effect of irrigation systems to reduce flow in the upper reaches covering the Bear River Basin [7]. Compared with three kinds of remote sensing ET model in the application of assimilation of soil moisture, Hunk pointed that SEBAL model is more suitable for TM images. Bastiaanssen applied SEBAL model to inversion sensible heat and latent heat flux from TM data in the cover flute hereby Basin Irrigation in Turkey [4]. Ricardo et al. have refined SEBAL model that can provide better ET estimation in agricultural areas and make more reliable estimates of ET from other surfaces including mountainous terrain by adopting an internal calibration procedure using public weather data and modifying empirical equations [8]. Kimura et al. used SEBAL model to estimate the ET of the Loess Plateau combined with Landsat-5 data [9]. Wim et al. did a detailed description of calculating ET through TM images by SEBAL model [10]. Bale et al. compared the ET from SEBAL model with the measured data by Lysimeter and demonstrates that SEBAL model has the ability to estimate spatial ET distribution [11]. Chang Y et al. used SEBAL model in cold and high-altitude mountainous regions to help manage water resources. In the recent research [12], Bhattarai et al. found a new automated method which uses an exhaustive search algorithm (ESA) to identify end member pixels (hot and cold pixels) in SEBAL model that could reduce time demands [13]. Pan have done a research with SEBAL model and ETM+ images of the Yellow River delta on remote sensing ET and analyzed the ET characteristics that have achieved good results. But there are few researches on ET inversion from SEBAL model of the response to the LUCC [14]. Previous research is the use of single remote sensing images to inversion ET and contrastly analyzed with land use conditions, which is difficult to meet the time-series on the changes and ignores the changes in ET induced by climate change.

In this study, two TM images and SEBAL model are used to inverse ET of 
Luoyugou watershed, and then, inversion results are got through validating ground data, showing that they are within the error range. Two integrated maps of land use are analyzed with ET changes on land use change matrix. In the context of climate change, ET in different land use types is obtained and a comprehensive analysis on the ET changes is done. The results indicate that the use of remote sensing data in combination with SEBAL model inversion regional ET has a broad applicable prospects for water resources management in the Loess Plateau and provides a basis and reference.

\section{Material and Methods}

\section{Study area}

Luoyugou watershed (between $34.4^{\circ} \mathrm{N}-34.7^{\circ} \mathrm{N}$ and $105.5^{\circ} \mathrm{E}-105.75^{\circ} \mathrm{E}$ ) is located in northern suburb of Tianshui City in Gansu Province of China (Figure 1), with an area of approximately $72.97 \mathrm{~km}^{2}$. It belongs to the Loess Plateau Loess Plateau. The elevation is between $1195 \mathrm{~m}$ and $1880 \mathrm{~m}$. The total slope is more than $10^{\circ}$. The basin has more than 230 major species of 49 families of higher plants and vegetation coverage accounts for $35.0 \%$ [15]. The study area has a continental semi-arid and semi-humid climate. The average annual rainfall is about 330 - $550 \mathrm{~mm}$, among which 70\% occurs during July to September. Affected by the monsoon season, seasonal precipitation distribution is very uneven. Dry weather is in winter and in spring, autumn and summer, rainfall concentrates. Although it is conducive to crop growth over the same period of rain and heat, each month changes largely due to inter-annual precipitation, which is prone to drought or flood. In the past 60 years, the average temperature is $11^{\circ} \mathrm{C}$ with annual precipitation and evaporation which are $518.8 \mathrm{~mm}$ and $1293.3 \mathrm{~mm}$ respectively (Figure 2). It shows that the dryness is 1.3 [16]. Nearly 20 years, the temperature increases significantly. From the year 1986 to 2008, annual temperature increases $0.95^{\circ} \mathrm{C}$ over 1951 to 1986 years. Rainfall shows fluctuations in

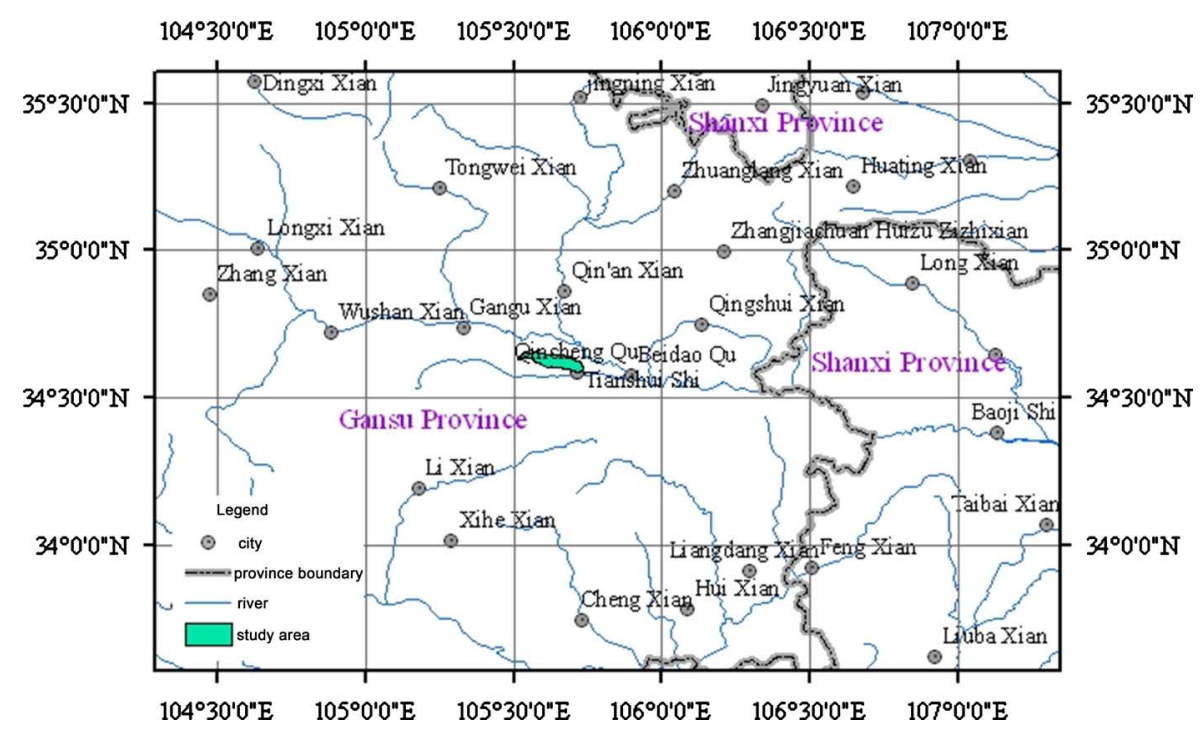

Figure 1. Location map of Luoyugou Watershed. 


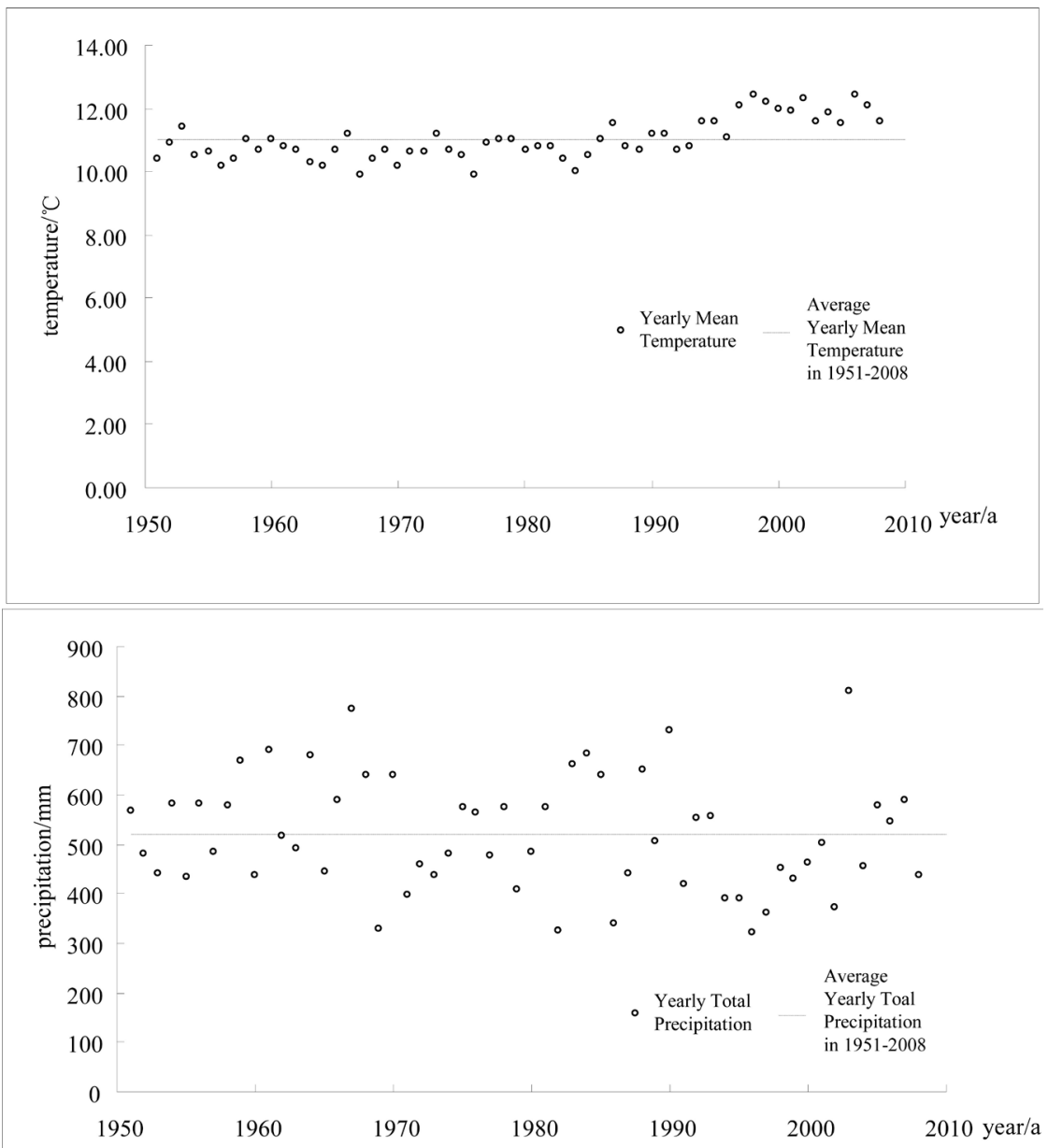

Figure 2. Changing trend curves of annual average temperature and rainfall in the study area.

trend in the past 60 years and the maximum appears in 2003, reaching 809.6 $\mathrm{mm}$, the minimum occurres in 1996, approximately $321.8 \mathrm{~mm}$.

\section{Land use}

Terrace, forest and unused land are the main land use type in Luoyugou watershed. Among those, sloping land and terraces accounted for 57.90\%. Forest, including trees, shrubs and economic forest and so on, accounts for $14.65 \%$ totally. The area of orchard accounts for $10.18 \%$, which is increasing gradually. Unused land is about $8.32 \%$, mainly in the high altitude and steep slope areas, which are scattered with grassland, bare rock and so on (Table 1).

\section{Data used}

The basic data source of SEBAL technique is satellite images and meteorological data. Landsat 5 satellite images were used in this study. The meteorological data such as average temperature and wind speed required by the technique were obtained from a continuously active meteorological station located in the study area.

The image data used in this study are shown in Table 2. The cloud amount of two images are less than $5 \%$ and $10 \%$ in the center and the surrounding respectively, 
meeting the study criteria. Five images are downloading from the NASA website.

Meteorological and hydrological data of Luoyugou watershed from 1986 to 2015 are got from the Yellow River Basin Management Committee Tianshui Soil and Water Conservation Experiment Station Field Observations. Empirical data for 2006 measured on the ground, measuring elements, methods, and observation equipment are shown in Table 3.

\section{Image processing}

Based on 1:1 million scale topographic maps of Luoyugou watershed and Landsat images, 20 Ground Control Points on the ground were selected for geometric

Table 1. Land use of Luoyugou Watershed in 2010.

\begin{tabular}{ccc}
\hline Land type & Subclass & Area $\left(\mathbf{k m}^{2}\right)$ \\
\hline Terracing & Sloping & 3287.77 \\
Terrace & - & 927.45 \\
Woodland & Tree & 665.48 \\
& shrub & 350.73 \\
& Woodland ground & 9.12 \\
Orchard & Economic forest & 40.69 \\
Natural grassland & - & 740.97 \\
Unused land & - & 366.14 \\
& Grassland & 472.28 \\
& Beach & 87.2 \\
& Bare rock & 37.76 \\
& Bare soil & 8.11
\end{tabular}

Table 2. Image information list.

\begin{tabular}{cccc}
\hline Serial Number & Acquired Date & Satellite & Satellite Sensor \\
\hline $1^{\text {rd }}$ & July 31, 1986 & Landsat-5 & Thematic Mapper (abbr. TM) \\
$2^{\text {nd }}$ & May 19, 2006 & Landsat-5 & Thematic Mapper (abbr. TM) \\
\hline
\end{tabular}

Table 3. Field observation forms.

\begin{tabular}{|c|c|c|c|}
\hline Observation Project & Observational method & Instrument & Observation time \\
\hline Rainfall & $\begin{array}{l}\text { Self-recording rain and ordinary } \\
\text { rain gauges }\end{array}$ & $\begin{array}{l}\text { SL1 Telemetry rain gauge; } \\
\text { DSJ2 Siphon self-recording rain gauge(made in Tianjin, } \\
\text { China); } 20 \mathrm{~cm} \text { standard SM1 rain gauges }\end{array}$ & Day \\
\hline ET & $\begin{array}{l}\text { Weighing and Depth measurement } \\
\text { method }\end{array}$ & Lysimeter, Evaporating dish & Day \\
\hline Air temperature & $1.2 \mathrm{~m}$ over the ground & Temperature Table & Hour \\
\hline Geothermal & Underground $5,10,15,20 \mathrm{~cm}$ & Ground temperature Table & Hour \\
\hline Humidity & $1.2 \mathrm{~m}$ over the ground & psychrometer & Hour \\
\hline Solar radiation & $\begin{array}{l}\text { Downlink radiation and upward } \\
\text { radiation }\end{array}$ & Solar Radiometer & Hour \\
\hline
\end{tabular}


correction and error control in less than 0.5 pixels. Combined with statistical data, such as relief maps, thematic maps and site investigation in 2006 to establish land interpretation symbols of the study area, and then apply the image processing software ERDAS 2013, using human-computer interaction and supervised classification approach to interpretation. Through verification by field survey data, interpretation accuracy is approximately $76 \%$. With the support of ArcGIS, 10.3, spatial overlay analysis method and spatial statistical analysis method were used to generate land use/cover change dynamics information and relevant statistics.

\section{ET Calculation}

\section{SEBAL Model Principle}

Solar radiation is the basis of surface energy exchange. When the radiation through the atmospheric attenuation to the surface, its energy is mainly used for heating the air and soil, as well as the promotion of water evaporation. SEBAL model uses the surface energy balance principle to calculate the ET [17] [18], whose equation is shown as follows:

$$
R_{n}=L E+G+H
$$

where $R_{n}$ is the surface net radiation flux $\left(\mathrm{W} / \mathrm{m}^{2}\right)$; $G$ is the flux of heat into the soil $\left(\mathrm{W} / \mathrm{m}^{2}\right), H\left(\mathrm{~W} / \mathrm{m}^{2}\right)$ is the sensible heat flux from the surface to the atmosphere and LE the latent heat flux $\left(\mathrm{W} / \mathrm{m}^{2}\right)$.

Instantaneous ET

Using the formula proposed by Pang to calculate the instantaneous ET [19], which is given below:

$$
E_{T i}=3600 L E / \lambda
$$

where $\lambda$ is the latent heat of vaporization $\left(2.49 \times 10^{6} \mathrm{~W} \cdot \mathrm{m}^{-2} / \mathrm{mm}\right)$. Potential ET coefficient $\left(E T_{r} F\right)$ is defined as the ratio of the instantaneous ET of each pixel and potential ET calculated by meteorological data.

Day ET

Because the diurnal variation of solar radiation flux density presents a sinusoidal relationship at any time, previous researches showed that there is a sine relationship between day ET and instantaneous ET [20] [21]. It can be got from 0 to $N_{E}$ for points.

$$
\frac{E_{T d}}{E_{n}}=\frac{2 N_{E}}{\pi \cdot \sin \left(\pi \cdot t / N_{E}\right)}
$$

where $E_{T d}$ is day ET $(\mathrm{mm}), E_{t i}$ is the instantaneous ET at time $t_{i}(\mathrm{~mm})$ and $t$ is time interval from sunrise to the time $t_{i}(\mathrm{~h}), N_{E}$ is hour numbers of day ET (h), whose length is from ET start time to ET declined to close to 0 . Generally both one hour after sunrise and before sunset, ET is close to 0 . Therefore, $N_{E}$ is less 2 hours than sunshine hours $\mathrm{N}(\mathrm{h} / \mathrm{d})$.

\section{Parameters solving}

Remote sensing image parameters solving

NDVI: Normalized Difference Vegetation Index (NDVI) reflects the density 
of vegetation cover and soil moisture characteristics. 1) NDVI is a best direction factor of vegetation condition and vegetation cover. Many studies have shown that NDVI is related to LAI (leaf area index), green biomass, vegetation coverage, and vegetation parameters of photosynthesis. 2) NDVI processed by ratio can partially eliminate the influence of the sun elevation angle, satellite observation angle, terrain, cloud shadows and atmospheric radiation, etc. 3) NDVI is obviously indicative to vegetation. Where vegetation occurs in a place, NDVI is positive and increases with the degree of vegetation cover. In this paper, the band 3 and 4 of TM images are used to obtain NDVI by the following formula

$$
\mathrm{NDVI}=\frac{\text { Band } 4-\text { Band } 3}{\text { Band } 4+\text { Band } 3}
$$

where NDVI is normalized difference vegetation index, band 3 and band 4 are wavelengths in red (i.e., visible light) and the reflective infrared bandwidths, respectively.

Surface albedo: Surface albedo is the ratio of the solar radiation flux that surface reflects in all directions to reach the surface and the total radiation flux. There are many ways to calculate surface albedo, in which Ma commonly used four streams remote sensing model to calculate the planetary albedo [22] [23]. Dale and Jeffrey discussed inversion surface albedo, evapotranspiration estimation from TIR remote sensing data [24]. XU applied the bidirectional reflectance model to get that the average surface albedo is retrieved separately in our country and the Qinghai-Tibet Plateau [25]. It is complicated to solve surface albedo with the model and difficult to achieve. Chen pointed out that in north-west, when the NDVI values from a small start increased gradually, surface albedo decreased rapidly [26]. NDVI values ranging from -0.2 to 0.2 are obvious in this process. Since then, with the vegetation index values continuing to increase, surface albedo is slowly declining. When NDVI value is greater than 0.5 , surface albedo changes have tended to smooth. By NDVI to build statistical model is difficult to ensure the accuracy of surface albedo, this article computes through the relationship between a broadband planetary albedo and surface albedo [6].

1) Spectral radiance is used to solve all the apparent narrow-band reflectance $\rho_{\lambda}$

$$
L_{\lambda}=\text { gain } \times Q C A L+o f f s e t
$$

where $L_{\lambda}$ is the spectral radiance, gain and offset can be obtained from header files; $Q C A L$ is the $\mathrm{DN}$ of a given pixel in the image.

$$
\rho_{\lambda}=\frac{\pi L_{\lambda} d_{r}^{2}}{E S U N_{\lambda} \cos (\theta)}
$$

Among them, $\rho_{\lambda}$ is the top of the atmosphere apparent reflectance, $d_{r}$ is the Sun-Earth distance (astronomical units), $E S U N_{\lambda}$ is the average solar spectral irradiance of the top atmosphere, whose value of each band has different specific parameters, as follows in the table [27] with that $\theta$ is the sun zenith angle (Table 4). 
Table 4. The values of $E S U N_{\lambda}$ for reflecting bands.

\begin{tabular}{cccccccc}
\hline Satellites/Band NO. & 1 & 2 & 3 & 4 & 5 & 7 & 8 \\
\hline Landsat4 & 1957.00 & 1825.00 & 1557.00 & 1033.00 & 214.90 & 80.72 & - \\
Landsat5 & 1957.00 & 1826.00 & 1554.00 & 1036.00 & 215.00 & 82.67 & - \\
Landsat7 & 1969.00 & 1840.00 & 1551.00 & 1044.00 & 225.70 & 82.07 & 1368.00 \\
\hline
\end{tabular}

Table 5. The values of $c_{\lambda}$ for reflecting bands.

\begin{tabular}{ccccccc}
\hline Band NO. & 1 & 2 & 3 & 4 & 5 & 7 \\
\hline Landsat4 & 0.2935 & 0.2737 & 0.2335 & 0.1549 & 0.0322 & 0.0121 \\
Landsat5 & 0.2928 & 0.2736 & 0.2330 & 0.1566 & 0.0328 & 0.0111 \\
Landsat7 & 0.2934 & 0.2741 & 0.2311 & 0.1555 & 0.0336 & 0.0122 \\
\hline
\end{tabular}

2) The upper bound of a wide-band atmospheric albedo $\alpha_{\tau}$

$$
\alpha_{\tau}=\sum c_{\lambda} \rho_{\lambda}(\lambda=1,2,3,4,5,7)
$$

where $c_{\lambda}$ was the weighting factor of band $\lambda$, which is defined as the percentage of band $\lambda$ radiation in the total radiation that can be obtained from the ratio of the potential energy of each band and the total potential energy. You can get scientific data of Landsat-7 from the query on the users' manual [7] The $c_{\lambda}$ value of each band is shown in Table 5 .

3) Surface albedo calculation

$$
\alpha=\frac{\alpha_{\tau}-\alpha_{\text {path }}}{\tau_{s w}^{2}}
$$

where, $\alpha_{\tau}$ is the reflectivity outside the atmosphere; $\alpha_{p a t h}$ is the value of the atmospheric path radiation, about $0.025-0.04$, generally take $0.03 ; \tau_{s w}$ is a one-way atmospheric transmittance that can be obtained from the DEM data [22].

\section{Energy balance equation parameters solving}

Net radiation: The regional distribution of surface net radiation flux is decided by the net short-wave radiation and net long-wave radiation commonly [28] [29], namely the Earth's surface radiation balance equation which can be expressed as

$$
R_{n}=Q(1-\alpha)+R_{l \downarrow}-R_{l \uparrow}
$$

where $R_{n}$ is the surface net radiation flux, $Q$ is Solar Radiation, $R_{l \downarrow}$ and $R_{l \uparrow}$ are the atmospheric downward long-wave radiation and the surface upward long-wave radiation, respectively; $\alpha$ is surface reflectivity.

The global solar radiation reaching the ground is

$$
Q=S_{0} d_{r}^{2} \sin h \cdot P
$$

where $S_{0}$ is the solar constant, whose value is $1366.67 \mathrm{~W} / \mathrm{m}^{2}, h$ is solar altitude angle, $d_{r}$ is the revised Sun-Earth distance, $P$ is atmospheric transparency coefficient, approximately 0.652 (Li et al., 2006).

Atmospheric downward long-wave radiation $R_{l \downarrow}$ (W/m²) (sunny) formula 


$$
R_{l \downarrow}=\left[1-a \exp \left(-b \frac{e_{0}}{T_{a}}\right)\right] \sigma T_{a}^{4}
$$

where $a=0.35, b=10.0 \mathrm{~K} / \mathrm{hPa}, T_{a}$ is atmospheric temperature in the thermometer screen $(\mathrm{K}), e_{0}$ is water vapor pressure in the thermometer screen $(\mathrm{hPa})$.

The surface upward long wave radiation $R_{l \uparrow}\left(\mathrm{W} / \mathrm{m}^{2}\right)$ is stated as following

$$
R_{l \uparrow}=\varepsilon \sigma T_{s}^{4}
$$

Where $\varepsilon$ is the surface emissivity, $\sigma$ is Stefan-Boltzmann constant, $\sigma=5.67 \times 10^{-8} \mathrm{~W} /\left(\mathrm{m}^{2} \cdot \mathrm{K}^{4}\right), T_{s}$ is surface temperature $(\mathrm{K})$.

Soil heat flux: Soil heat flux is an important part of the heat balance equation that refers to the part of the energy stored in the soil and vegetation due to conduction, which characterizes heat exchange between the surface and the deep underground.

According to Ma method to calculate [22]

$$
G=\left\{\begin{array}{l}
\frac{T_{s}}{\alpha}\left(0.0032 \alpha+0.0062 \alpha^{2}\right)\left(1-0.978 N D V I^{4}\right) \times R_{n}(\text { Veg }) \\
0.20 R_{n}(\text { Soil })
\end{array}\right.
$$

where $T_{S}$ is the surface temperature; $\alpha$ is surface albedo, $R_{n}(V e g)$ is the Surface net radiation flux of Vegetation $\left(\mathrm{W} / \mathrm{m}^{2}\right), R_{n}(V e g)$ is the Surface net radiation flux of Soil $\left(\mathrm{W} / \mathrm{m}^{2}\right), N D V I$ is the value of Normalized Difference Vegetation Index.

Sensible heat flux: Sensible heat flux is the energy dissipated into the atmosphere due to conduction and convection and also a function of the atmospheric stability, wind speed and surface roughness [30]. Sensible heat flux is the focus and difficult to calculate by SEBAL model. It is a complicated process and calculation accuracy affects the ET accuracy directly. The general formula is

$$
H=\rho C_{p}\left(T_{0}-T_{a}\right) / r_{a}
$$

where $\rho$ is the air density, $C_{p}$ is the constant pressure specific heat, $\rho C_{p}$ is the volume of air heat capacity, this paper takes constant 120. $r_{a}$ is aerodynamic resistance, which is a complex variable with many parameters. There are many simulation methods [1]. This study adopts a simple single-layer model to calculate.

$$
r_{a}=\frac{1}{k^{2} U}|\ln | \frac{z-d}{z_{0 h}}\left|-\psi_{s h}\right| \ln \left|\frac{z-d}{z_{0 m}}\right|-\psi_{s m} \mid
$$

where $k$ is von Karman constant (0.41), $z$ is the reference height, usually $2 \mathrm{~m}, U$ is the reference height of wind speed, namely, heat and momentum stability correction items, $d$ is zero plane displacement (m).

\section{Results}

\section{Vegetation coverage}

In Luoyugou watershed, artificial locust forest vegetation domain here; areas 
of economic forest land is in the rapid increasing; shrub and grass grow naturally. As a whole (Figure 3 and Figure 4), upper reaches of Luoyugou watershed, vegetation coverage reaches a maximum of $36.7 \%$. It is mainly due to high elevation and steep slope which cause that vegetation consisting mainly of black locust forests and natural grasslands. In addition, because of the impact of returning farmland to forest policies, vegetation has been better protected. The degree of vegetation coverage in lower reaches is the minimum, to $27.7 \%$. It is due to Tianshui city whose underlying surface is the artificial construction and residential areas located the lower reaches. So vegetation coverage is low in the lower reaches of Luoyugou watershed.

\section{Surface albedo}

Figure 5 is the surface albedo map got by remote sensing. We can see the reflectivity of Luoyugou watershed is between $0.07-0.28$, with the largest reflectance in the Nanjiawan River basin, more than 0.20 . Areas with sparse vegetation cover which mainly locate in the lower basin and the central city of Tianshui are the smallest. The albedo of northern is smaller than the southern, while the slope of the southern is significantly larger than the northern in the middle reaches. With dense vegetation and abundant water in summer, so there is a high reflectivity on the southern slope. By the image histogram, we can obtain that the frequency peak of 0.23 mainly lies on the middle and upper reaches of the basin. Table 6 is the comparison surface reflectance values measured with the inversion under different land use types. Inversion value is greater than the measured

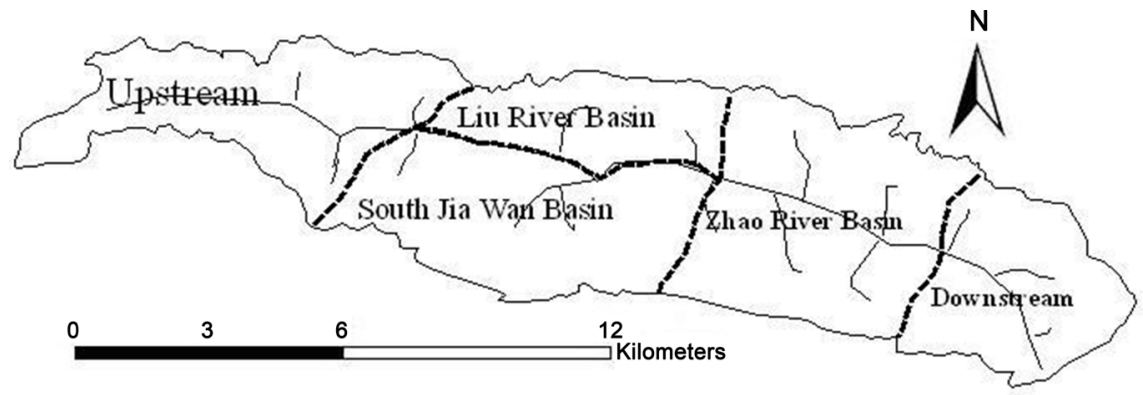

Figure 3. Watersheds of study area.

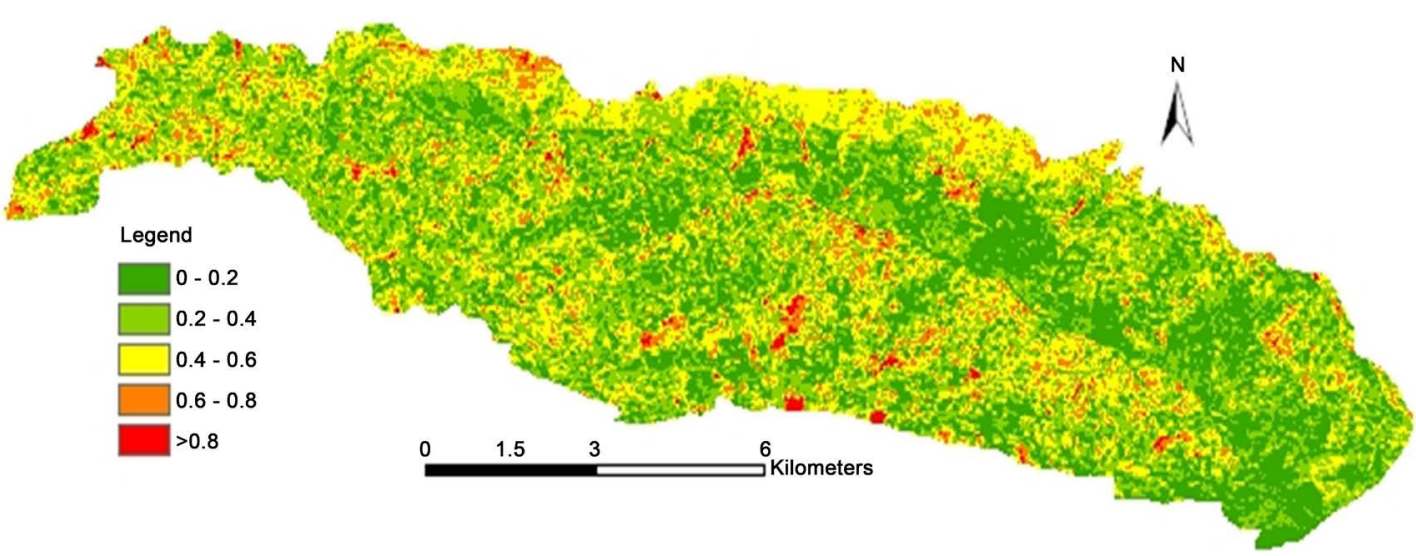

Figure 4. Vegetation coverage distribution map of study area. 
value, of which the maximum error is $18.75 \%$, with an average error of $10.25 \%$. Inversion value has a higher accuracy.

\section{Day ET}

Figure 6 shows that the day inversion ET in the study area is $0.3-4.2 \mathrm{~mm}$, and the average is $2.96 \mathrm{~mm}$. The upper basin is essentially larger than the lower reaches in ET on the spatial distribution. In the upper reaches, there are many woodland and grasslands, vegetation coverage is high. So the actual ET of water is large, more than $2 \mathrm{~mm}$, and in downstream, with large areas of loess hilly, gully area and the residential area, surface exposed and the ET generally is less than $1.5 \mathrm{~mm}$.

Three small cylindrical lysimeter set up in the study area measure the ET of

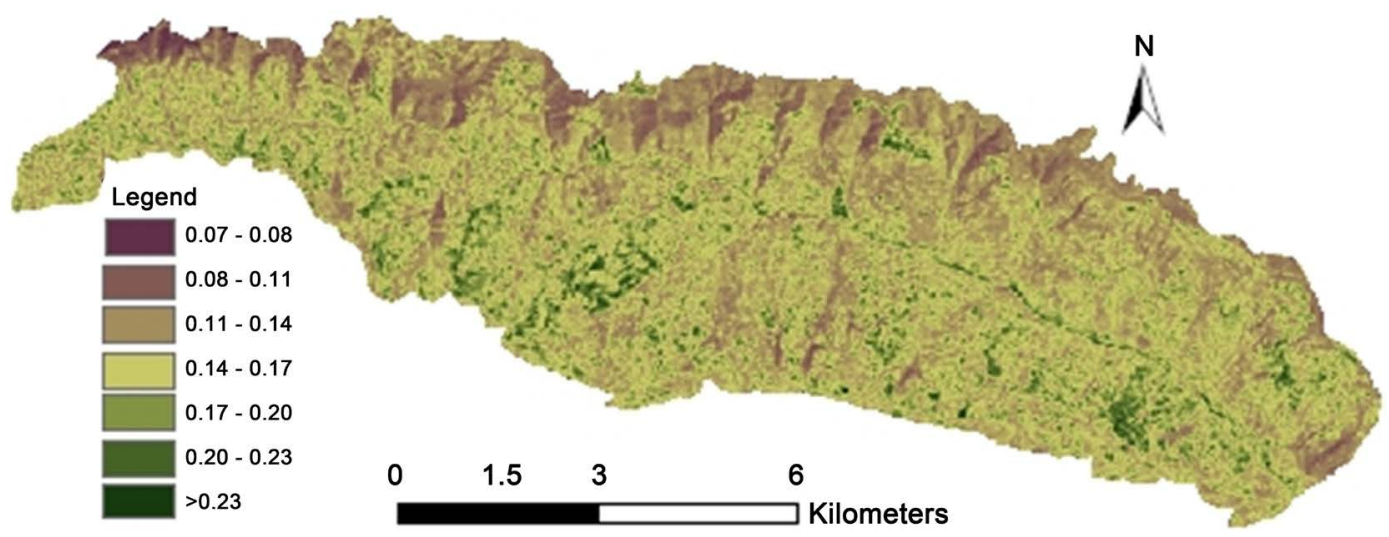

Figure 5. Surface albedo distribution maps of study area.

Table 6. Reflectance values of the inversion compared with measured of various land use types.

\begin{tabular}{ccc}
\hline Land use types & Measured value & Inversion value \\
\hline Bare soil & 0.09 & 0.12 \\
Terrace & 0.10 & 0.15 \\
Natural grassland & 0.14 & 0.16 \\
orchard & 0.15 & 0.16 \\
Woodland & 0.16 & 0.19 \\
Water body & 0.25 & 0.27 \\
\hline
\end{tabular}

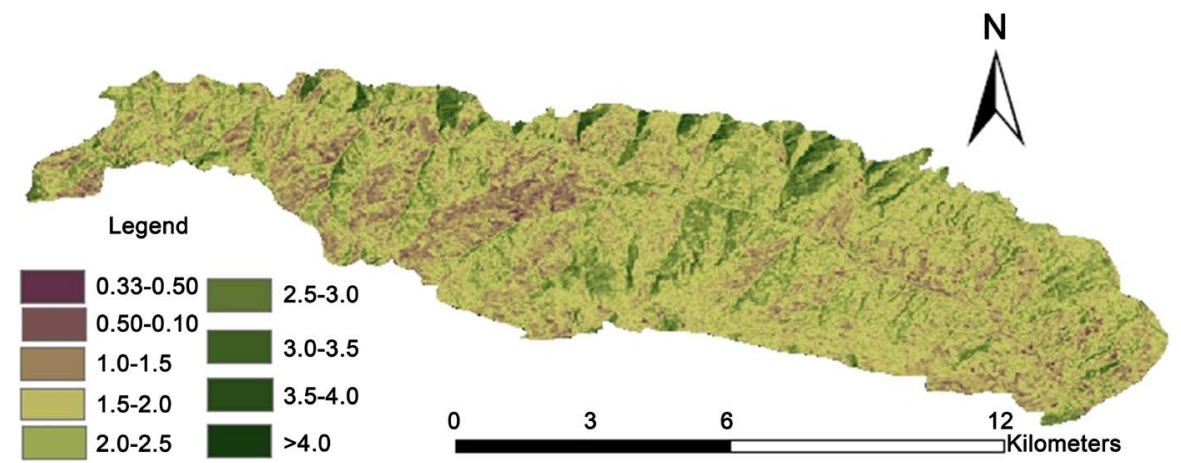

Figure 6. ET inversion map of 2006. 
bare soil, farm land, grass land and shrub land. We can weigh on time everyday. The ET projected out by weighing the weight of lysimeter in different periods can be used as the validation data of estimates. Results show that the average error is $0.51 \mathrm{~mm}$ and the average relative error is $12.68 \%$, taking possible error caused by parameters, time-scale expansion and the date of the instability of atmospheric conditions into account, and inversion accuracy is reasonable.

\section{Impact of land use and cover changes on $E T$}

In order to understand the relationship between LUCC and the ET, analyzing Figure 6 and Figure 7, we can see that the spatial distribution of ET is relevant to land use types. High-figure areas of ET are mainly on both sides of Luoyugou River and high vegetation coverage area; Low value area is mainly in the vegetated areas with the construction land, bare land and low vegetation coverage. It states that the basic characteristics of land use/cover control the characteristics of the regional distribution of ET in the study area.

\section{Changes in land use}

Interpreted remote sensing image in 1986 and the actual tone paint of land use study area in 2006, we access to the condition of land use in 1986 and 2006. As can be seen from Table 7, the main land use types in the study area are woodland,

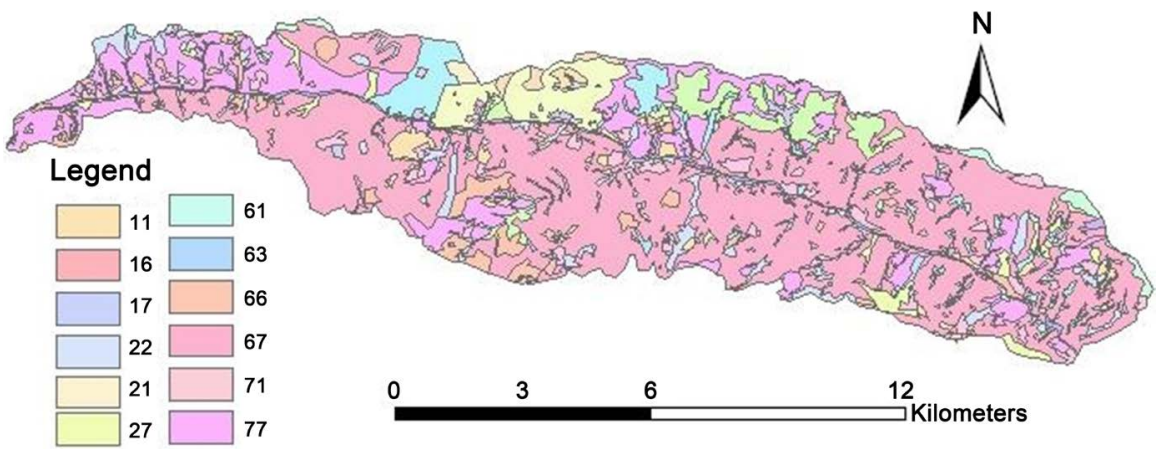

Figure 7. Spatial transition of the land types in study area (1 representative of the orchard, 2 representatives of woodland, 3 representatives of the construction land, 6 on behalf of sloping land, 7 on behalf of terraced fields, 67 on behalf of sloping land transfer to the terrace, 11 on behalf of the orchard is still orchard, other label the same meaning).

Table 7. Land use/cover change matrix between 1986 and 2006 (Unit: hm²).

\begin{tabular}{|c|c|c|c|c|c|c|c|}
\hline \multirow[b]{2}{*}{ Year 1986} & \multicolumn{7}{|c|}{ Year 2006} \\
\hline & orchard & Woodland & Grassland & Construction land & Terrace & Sloping terrace & Total \\
\hline orchard & 1840.95 & & & & 27.13 & 92.34 & 1960.42 \\
\hline Woodland & & 4158.50 & & & & 1408.84 & 5567.34 \\
\hline Grassland & & & 3013.02 & & & & 3013.02 \\
\hline Construction land & & & & 2371.96 & & & 2371.96 \\
\hline Terrace & 12.51 & 7.70 & 0.10 & 1.86 & 2839.50 & $35,935.00$ & $38,796.66$ \\
\hline Sloping terrace & 1.90 & 2.14 & & 0.73 & 0.23 & $10,950.12$ & $10,955.13$ \\
\hline Total & 1855.36 & 4168.34 & 3013.12 & 2374.55 & 2866.85 & $48,386.30$ & $62,664.53$ \\
\hline
\end{tabular}


sloping land and terraces. The cover of three farming types take up about $82.2 \%$ of the total land area; compared with 1986, in 2006, the terrace area and woodland increased by $107.5 \%$ and $275.0 \%$ respectively, with a reduction of $76.5 \%$ for sloping terrace.

\section{ET change}

During the study period (Figure 7), only a very small area of the district forest land transfer to sloping land, while part of the grassland, shrub land and terraces evolutes into forest land, which has caused that forest land area increases in Luoyugou watershed and part of the slope farmland transfer into residential areas and terraces. But on the influence of returning farmland to forest policies, terracing land shift to forest and residential land again, which makes slope terracing in a significant reduction, the cover terracing shifted from slope terracing in a significant increase and structure of land use in optimization.

As the two remote sensing image acquisition phases in different period, it will be not well reflected that the evolution of ET is with the trends of LUCC by use of the absolute value of ET directly. Therefore, this study uses analysis method of non-dimensional, which gets the ET data into $[0,1]$ after the ET value of two-phase processed in standardization. We should have further calculations between the margins. And then, the changes of the ET pattern will be achieved for nearly 20 years. Based on an average interval five classifications, treating $-0.5,0,0.5$ as the threshold value, we can get changing ET map from 1986 to 2006 years (Figure 8 ).

Than that in 1986, the area with significantly increased regional ET in 2006 accounted for $47.6 \%$, and significantly reduced accounted for $13.2 \%$, indicating that an overall river basin ET significantly increased. Figure 3 and Table 8 are analyzed in an integrated manner: The increased region mainly lies in the upper reaches and the Nanjiawan Basin, accounting for more than 35\% of the total. The significantly reduced region are mainly in the downstream and Zhao River basin, accounting for $8.3 \%$. ET changes in spatial distribution are relevant to vegetation coverage; ET increase corresponds to a higher degree of vegetation coverage area and the reduction corresponds to the lower vegetation coverage area. With the reason that the increased ET regions are mostly from the slope to a terraced farmland or forest land and changing land use types are conducive to the Earth's

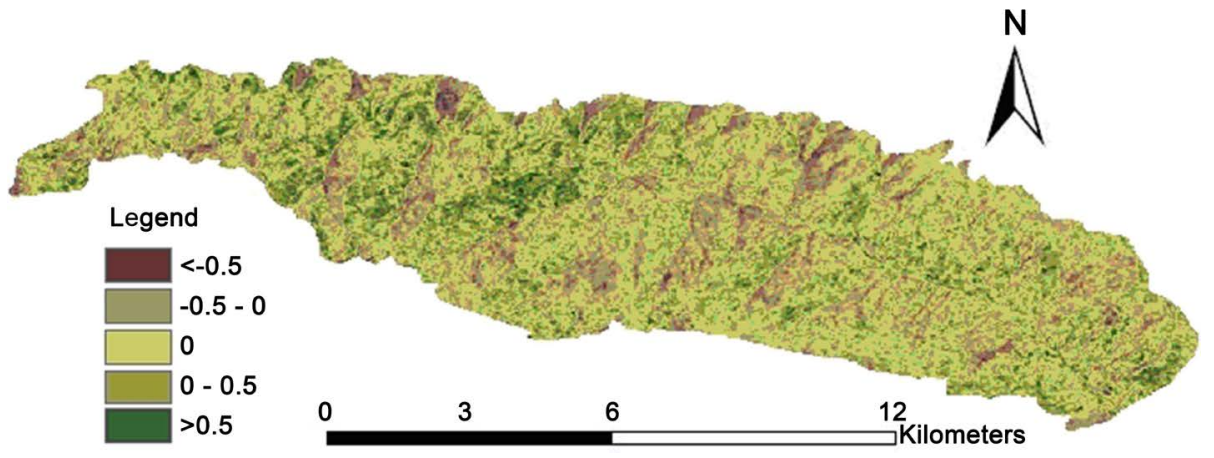

Figure 8. Changes of ET from 1986 to 2006. 
Table 8. ET of watersheds in Luoyugou watershed on 31 July, 1986.

\begin{tabular}{cccc}
\hline Watershed & Min & Max & Average \\
\hline Downstream & 2.056 & 3.562 & 2.910 \\
Zhao River Basin & 1.936 & 3.609 & 2.961 \\
Upstream & 2.104 & 3.712 & 2.997 \\
South Jia Wan Basin & 1.976 & 3.500 & 2.864 \\
Zhao River Basin & 1.892 & 3.561 & 3.021 \\
\hline
\end{tabular}

surface ET, ET increased. The areas with significantly reduced ET are mainly concentrated in the bare land and buildings land, the basic change in the regional multi-terraced crop is due to structural changes, as well as natural woodland and grassland vegetation coverage changes.

In comparison, two periods of different land use/cover types of the distribution under ET do not change significantly. ET characteristics are the largest body of water, followed by terraced fields and forest land, with the construction land minimum. That terrace ET differs in two periods is mainly due to the obvious transferring between farmland and terraced slope in the research area for 20 years, as well as changes in the structure of field crops and in crop coverage. Terrace day ET in 1986 amount to $1.65 \mathrm{~mm}$, with the amount of water daily ET to $4.20 \mathrm{~mm}$, and the construction site daily ET quantity to $1.05 \mathrm{~mm}$. However, Terrace day ET in 1986 amount to $1.86 \mathrm{~mm}$, with water daily ET to $4.53 \mathrm{~mm}$ and the construction site daily ET quantity to $1.46 \mathrm{~mm}$. Through the contrast of daily average temperature in the two years, we can get that due to global warming, the average temperature in 2006 is higher than that in 1986; the annual rainfall trend to decrease under the action of various climatic factors; and the amount of each type in 2006 is greater than that in 1986.

\section{Daily ET change of different land}

Through the analysis of daily evapotranspiration of different land use, the spatial distribution pattern of daily evapotranspiration in this region was obtained (Figure 9): the daily evapotranspiration of different land use types had significant differences. Daily evapotranspiration of water and wood land was the largest, followed by terraces and grasslands, and construction land was the smallest. The histogram of forest evapotranspiration has a double peak structure with a standard deviation of $0.26 \mathrm{~mm}$. The evapotranspiration histogram of terrace, grass land, and sloping farmland has a single peak structure, the average daily ET $2.9 \mathrm{~mm}, 2.9 \mathrm{~mm}$ and $3 \mathrm{~mm}$ respectively.

\section{Conclusions}

We used TM images and meteorological data to inverse ET of Luoyugou watershed based on SEBAL model, and verification of ground data shows that the accuracy of the inversion is within the error range (10.25\%). The results indicate that the use of remote sensing data in combination with SEBAL model inversion regional ET has high accuracy and a broad applicable prospects. 


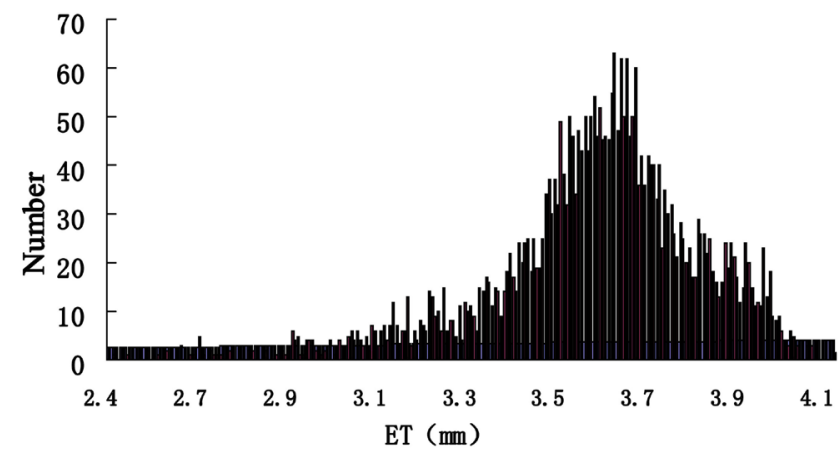

(a) wood land

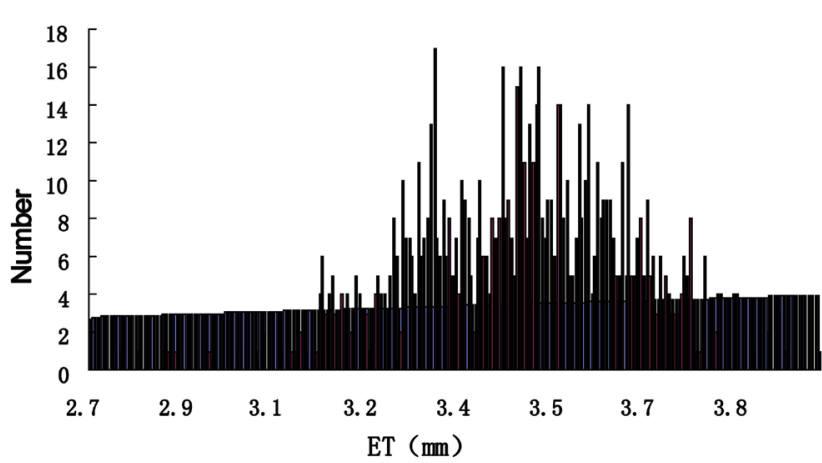

(c) water land

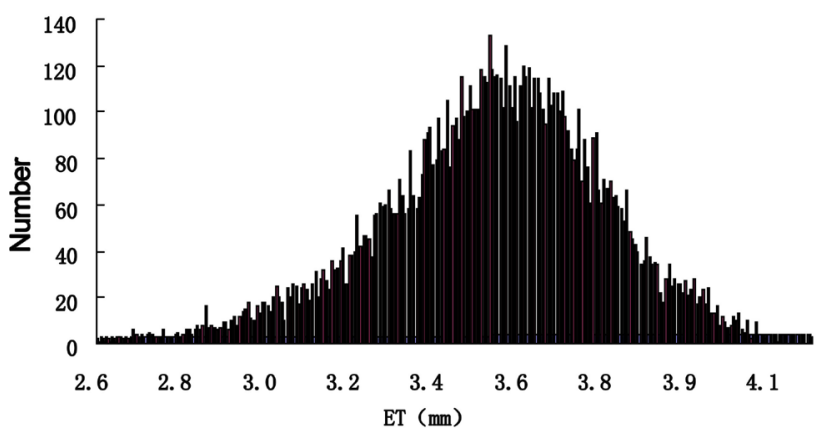

(e) sloping land

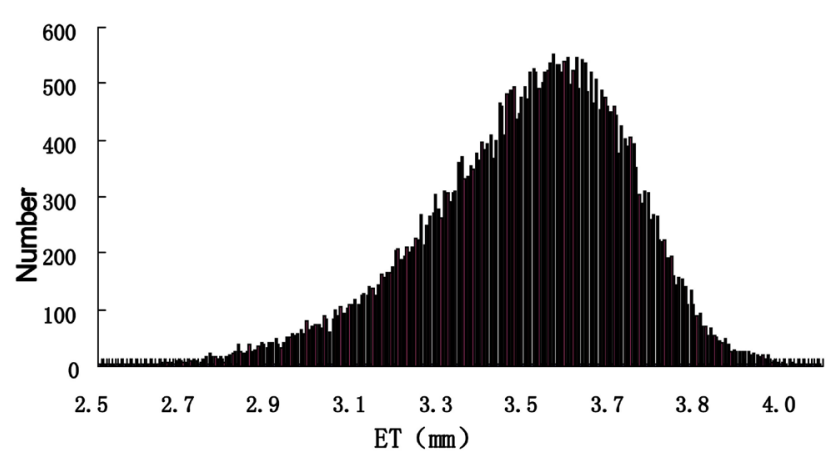

(b) Terrance

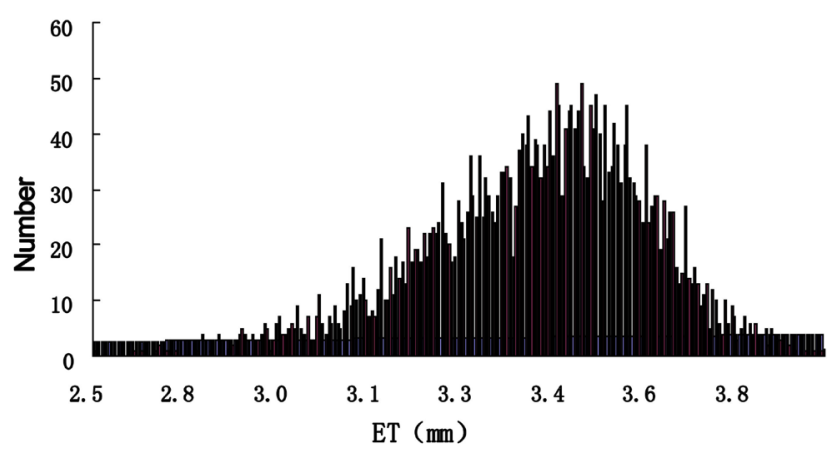

(d) construction land

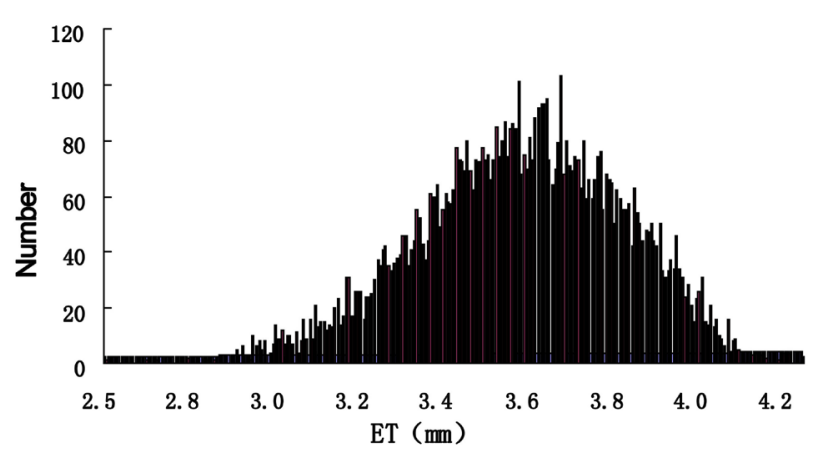

(f) grass land

Figure 9. Daily ET changes of different lands.

Land use/cover condition is an important factor that affects ET. And land-use structure is one of the important indicators for sustainable development which measures a region's ecological environment [31]. Remote sensing technology has the incomparable superiority over the traditional methods in the study at regional ET and characteristics of land surface. It is timely, efficiently economic and has high credibility.

The remote sensing studies have shown that land use and cover changes have extremely significant change in the study area nearly 20 years, with total changing area of $87.03 \%$. Terraced fields, natural vegetation, and the area of construction increase in varying degrees (increased by $275.0 \%, 17.05 \%, 14.32 \%$ ); cultivated land of sloping area and bare land decrease sharply (decrease by $76.5 \%$, 
respectively with $20.31 \%$ ).

Compared with 1986, in 2006, significantly increased region of ET accounts for $47.6 \%$ of the total area of Luoyugou watershed and significantly reduced to 13.2\%. The spatial distributions of ET and the type of land use and cover situation have certain relationship. The increased regions of ET are mostly transferred from the sloping land to terraced fields and woodlands. The changes in land-use types are conducive to ET of the Earth's surface, so ET increased. The areas where ET significantly reduced are mainly concentrated in the bare land and building land. Characteristics of land using and cover basically control the regional distribution of ET of the study area.

The daily evapotranspiration of different land use types had significant differences. Daily evapotranspiration of water and wood land was the largest, followed by terraces and grasslands, and construction land was the smallest.

After getting the regional ET by approach of using remote sensing and making a combination of land-type classification, we can obtain ET of the forest land, agricultural crops and urban land and so on. And then, we can assess the type of ET patterns of land use and water resources status etc. All these will provide a scientific basis for land surface process, crop yield assessment, saving agricultural water and other studies.

\section{Acknowledgements}

The study was sponsored by the Fundamental Research Funds for the Central Universities (Grant No. TD2011-2).

\section{Conflicts of Interest}

The authors declare no conflicts of interest regarding the publication of this paper.

\section{References}

[1] Yi, Y.H., Yang, D.W., Liu, Y. and Xu, D. (2008) Review of Study on Regional ET Modeling Based on Remote Sensing. Journal of Hydraulic Engineering, 39, 1118-1124.

[2] Mo, X.G. (1996) Review on Regional Evaporation. Advances in Water Science, 7, 180-185.

[3] Cao, X.M., Wang, J.L., Chen, X., Gao, Z.Q., Yang, F. and Shi, J.K. (2013) Multiscale Remote-Sensing Retrieval in the Evapotranspiration of Haloxylon ammodendron in the Gurbantunggut Desert, China. Environmental Earth Sciences, 69, 1549-1558. https://doi.org/10.1007/s12665-012-1989-0

[4] Bastiaanssen, W.G.M. (2000) SEBAL-Based Sensible and Latent Heat Fluxes in the Irrigated Gediz Basin, Turkey. Journal of Hydrology, 229, 87-100. https://doi.org/10.1016/S0022-1694(99)00202-4

[5] Boegh, E., Soegaard, H. and Thomsen, A. (2002) Evaluating Evapotranspiration Rates and Surface Conditions Using Landsat TM to Estimate Atmospheric Resistance and Surface Resistance. Remote Sensing of Environment, 79, 329-343. https://doi.org/10.1016/S0034-4257(01)00283-8 
[6] Zeng, L.H. and Song, K.S. (2008) Applying Landsat Data and SEBAL Model to Inverse Regional ET and Its Parameters Estimation. Remote Sensing Technology and Application, No. 6, 255-263.

[7] Allen, R.G., Tasumi, M., Morse, A. and Trezza, R. (2005) A Landsat-Based Energy Balance and Evapotranspiration Model in Western US Water Rights Regulation and Planning. Irrigation and Drainage Systems, 19, 251-268.

https://doi.org/10.1007/s10795-005-5187-Z

[8] Ricardo, M.G., Terry, M. and David, W.M. (2005) The Inappropriate Use of Crop Transpiration Coefficients (Kc) to Estimate Evapotranspiration in Arid Ecosystems: A Review. Arid Land Research and Management, 19, 285-295. https://doi.org/10.1080/15324980590951469

[9] Kimura, R., Bai, L., Fan, J., Takayama, N. and Hinokidani, O. (2007) Evapo-Transpiration Estimation over the River Basin of the Loess Plateau of China Based on Remote Sensing. Journal of Arid Environments, 68, 53-65. https://doi.org/10.1016/j.jaridenv.2006.03.029

[10] Wim, J.T., William, P.K., Martha, C.A. and Andrew, N.F. (2007) An Intercomparison of the Surface Energy Balance Algorithm for Land (SEBAL) and the Two-Source Energy Balance (TSEB) Modeling Schemes. Remote Sensing of Environment, 108, 369-384. https://doi.org/10.1016/j.rse.2006.11.028

[11] Bala, A., Rawat, K.S. and Misra, A.K. (2015) Assessment and Validation of Evapotranspiration Using SEBAL Algorithm and Lysimeter Data of IARI Agricultural Farm. Geocarto International, 2015, 739-764.

[12] Chang, Y., Ding, Y. and Zhao, Q. (2016) Remote Estimation of Terrestrial Evapotranspiration by Landsat 5 TM and the SEBAL Model in Cold and High-Altitude Regions: A Case Study of the Upper Reach of the Shule River Basin, China. Hydrological Processes, 31, 1-11.

[13] Bhattarai, N., Quackenbush, L.J. and Im, J. (2017) A New Optimized Algorithm for Automating Endmember Pixel Selection in the SEBAL and METRIC Models. Remote Sensing of Environment, 196, 178-192. https://doi.org/10.1016/j.rse.2017.05.009

[14] Pan, Z.Q., Liu, G.H. and Zhou, C.H. (2003) Dynamic Analysis of Evapotranspiration Based on Remote Sensing in Yellow River Delta. Journal of Geographical Sciences, 13, 408-415. https://doi.org/10.1007/BF02837878

[15] Yu, X.X., Zhang, X.M. and Li, J.L. (2009) Process and Mechanism of Soil Erosion. Beijing Science Press, Beijing, 48-54.

[16] Shen, Z.H., Zhang, X.S. and Jin, Y.X. (2000) Gradient Analysis of the Influence of Mountain Topography on Vegetation Pattern. Acta Phytoecologica Sinica, 24, 430-435.

[17] Mohamed, E., Psilovikos, A., Manakos, I. and Perakis, K. (2011) Application of the Sebs Water Balance Model in Estimating Daily Evapotranspiration and Evaporative Fraction from Remote Sensing Data over the Nile Delta. Water Resources Management, 25, 2731-2742. https://doi.org/10.1007/s11269-011-9835-9

[18] Tian, H., Wen, J., Wang, C.H., Liu, R. and Lu, D.R. (2012) Effect of Pixel Scale on Evapotranspiration Estimation by Remote Sensing over Oasis Areas in North-Western China. Environmental Earth Sciences, 67, 2301-2313. https://doi.org/10.1007/s12665-012-1677-0

[19] Pang, Z.G., Fu, J.E. and Li, J.R. (2004) Remote Sensing Model for Estimating ET Based on Energy Balance. Advances in Water Science, 15, 364-369. 
[20] Toby Carlson, N., William, C.J. and Robert, G.R. (1995) A New Look at the Simplified Method for Remote Sensing of Daily Evapotranspiration. Remote Sensing of Environment, 54, 161-167. https://doi.org/10.1016/0034-4257(95)00139-R

[21] José, L.C., Christopher, M.U.N., John, H.P. and William, P.K. (2008) Daily Evapotranspiration Estimates from Extrapolating Instantaneous Airborne Remote Sensing ET Values. Irrigation Sciences, 27, 67-81. https://doi.org/10.1007/s00271-008-0122-3

[22] Ma, Y.M., Wang, J.M., Menenti, M. and Bastiaanssen, W. (1999) Estimation of Flux Densities over the Heterogeneous Land Surface with the Aid of Satellite Remote Sensing and Field Observation. ACTA Meteorologica Sinica, 57, 180-189.

[23] Ma, Y.M., Liu, D.S., Wang, J.M., Huang, R.H., Su, Z.B. and Gao, F. (2003) Study on Land Surface Parameters over Inhomogeneous Landscape of Dunhuang Area by Using Satellite Data. Plateau Meteorology, 22, 531-536.

[24] Dale, A.Q. and Jeffrey, C.L. (1999) Thermal Infrared Remote Sensing for Analysis of Landscape Ecological Processes: Methods and Applications. Landscape Ecology, 14, 577-598. https://doi.org/10.1023/A:1008168910634

[25] Xu, X.K. and Liu, S.H. (2002) Deriving Monthly Means Surface Albedo of China. Acta Meteorologica Sinica, 60, 215-220.

[26] Chen, Y.H., Li, X.B. and Shi, P.J. (2001) Estimation of Regional Evapotranspiration over Northeast China Using Remote Sensing. Journal of Geographical Sciences, 11, 140-148. https://doi.org/10.1007/BF02888684

[27] (2002) Landsat-7 Science Data User's Handbook. Landsat Project Science Office, NASA Goddard Space Flight Center, Greenbelt.

[28] Guo, X.Y. (2005) ET Distribution of the Heihe River Basin Using Remote Sensing Data. Progress in Natural Science, 15, 1266-1270.

[29] Zohrab, S., Rawazir, A.S., Bleiweiss, M., Skagges, R. and Longworth, J. (2009) Using Remote Sensing to Evaluate the Spatial Variability of Evapotranspiration and Crop Coefficient in the Lower Rio Grande Valley, New Mexico. Irrigation Science, 28, 93-100. https://doi.org/10.1007/s00271-009-0178-8

[30] Li, S.B. and Zhao, C.Y. (2006) Estimating ET Based on Energy Balance in Guanchuan River Basin Using Remote Sensing. Remote Sensing Technology and Application, 21, 521-526.

[31] Liu, C.S., Gao, Z.Q. and Gao, W. (2007) Retrieval ET and Land Surface Temperature in Response to Land Use/Cover Change Based on Remote Sensing Data. Transactions of the CSAE, 23, 1-8. 